\title{
Editorial
}

\section{Biophotonics symposium - A scientific cruise}

\author{
Biophotonik-Symposium - Eine wissenschaftliche Kreuzfahrt
}

DOI 10.1515/plm-2014-0038

Biophotonics is a rapidly developing research area that is gaining in popularity particularly as the diagnostic techniques are non-invasive and have a high spatial resolution. Furthermore, novel optical sources provide opportunities for the accurate delivery of radiation to the target for diagnostic, therapeutic and surgical tasks as well as for manipulation of biological objects from tissue to cellular level [1-6]. Several optical techniques, in particular, optical coherence tomography (OCT), have already been translated from laboratory bench to the clinic $[7,8]$.

This special issue presents a collection of papers based on reports delivered at the IV Biannual International Symposium "Topical Problems of Biophotonics 2013”. The symposium took place in July 2013, and was jointly organized by the Institute of Applied Physics of the Russian Academy of Sciences, the Nizhny Novgorod State Medical Academy and the University of Nizhny Novgorod in collaboration with Gycom Ltd., Kvantron-NN Ltd., and the Government of Nizhny Novgorod Region. Two hundred and nine participants from 21 countries took part in the symposium. The scientific program included three parallel topical conferences: "Optical Bioimaging”,
"Nanobiophotonics", and "Neurobiophotonics"; as well as four workshops: "Advanced Laser Applications in Biomedicine", "Clinical Biophotonics", "Biophotonics in Stem Cell Research and Developmental Biology" and "Next Generation Biophotonics for Biology, Pharmacology, and Medicine" (co-organized by SkTech), thus covering a broad spectrum of topics in biophotonics.

The present issue includes both review and research papers illustrating the wide range of these conference topics which varied from microscopic studies at subcellular scale to application of optical techniques for diagnostics in clinical environment.

Subcellular studies are presented in the paper from Elagin et al. [9] which discusses the optimization of the penetration of nanoagents into cells. A set of five papers covers different aspects of application of OCT technique in biology and medicine. They range thematically from OCT monitoring of electro-kinetic response in biotissues [10] and the effect of compression in OCT diagnostics of skin [11] to clinical OCT applications, which include dose distribution monitoring in radiation therapy [12] and diagnosing inflammatory diseases of ear, nose, and throat [13]. Matveev et al. [14] present the current state of OCT elastography, a method that is the subject of active development.
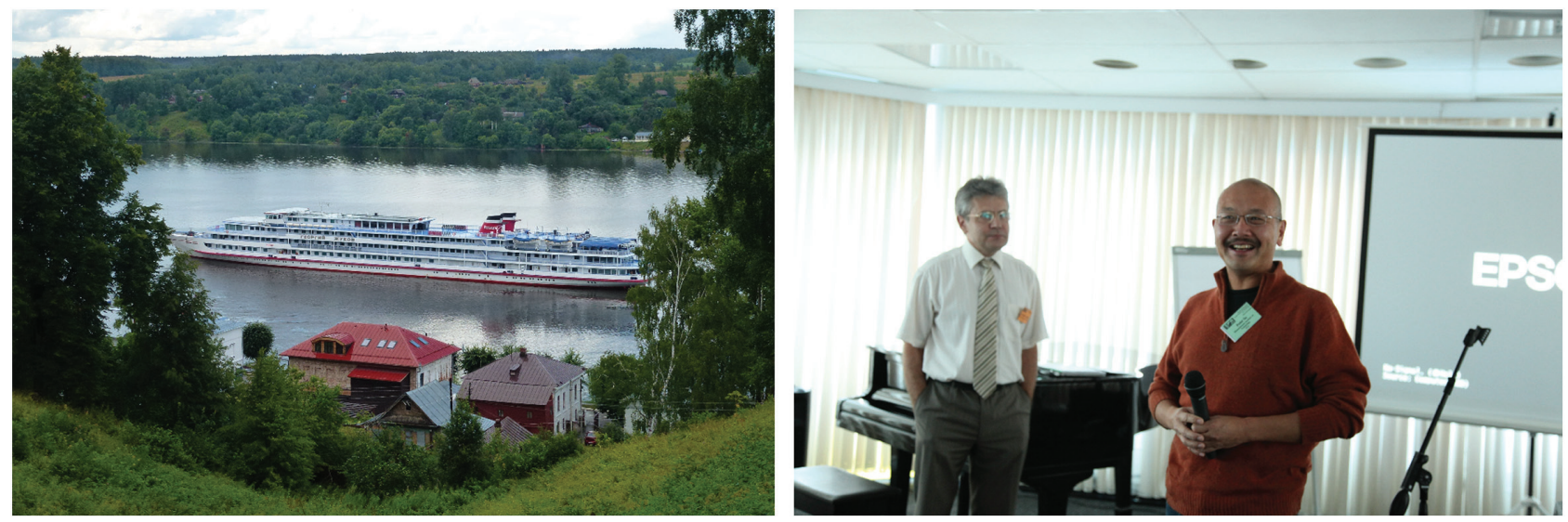

Left: Conference site: Cruise ship „Georgy Zhukov “at Plyos (photograph by H. Stepp). Right: Conference chairs Prof. A.M. Sergeev (on the left) and Prof. P. So (on the right) at the opening ceremony (photograph by S. Krotova). 


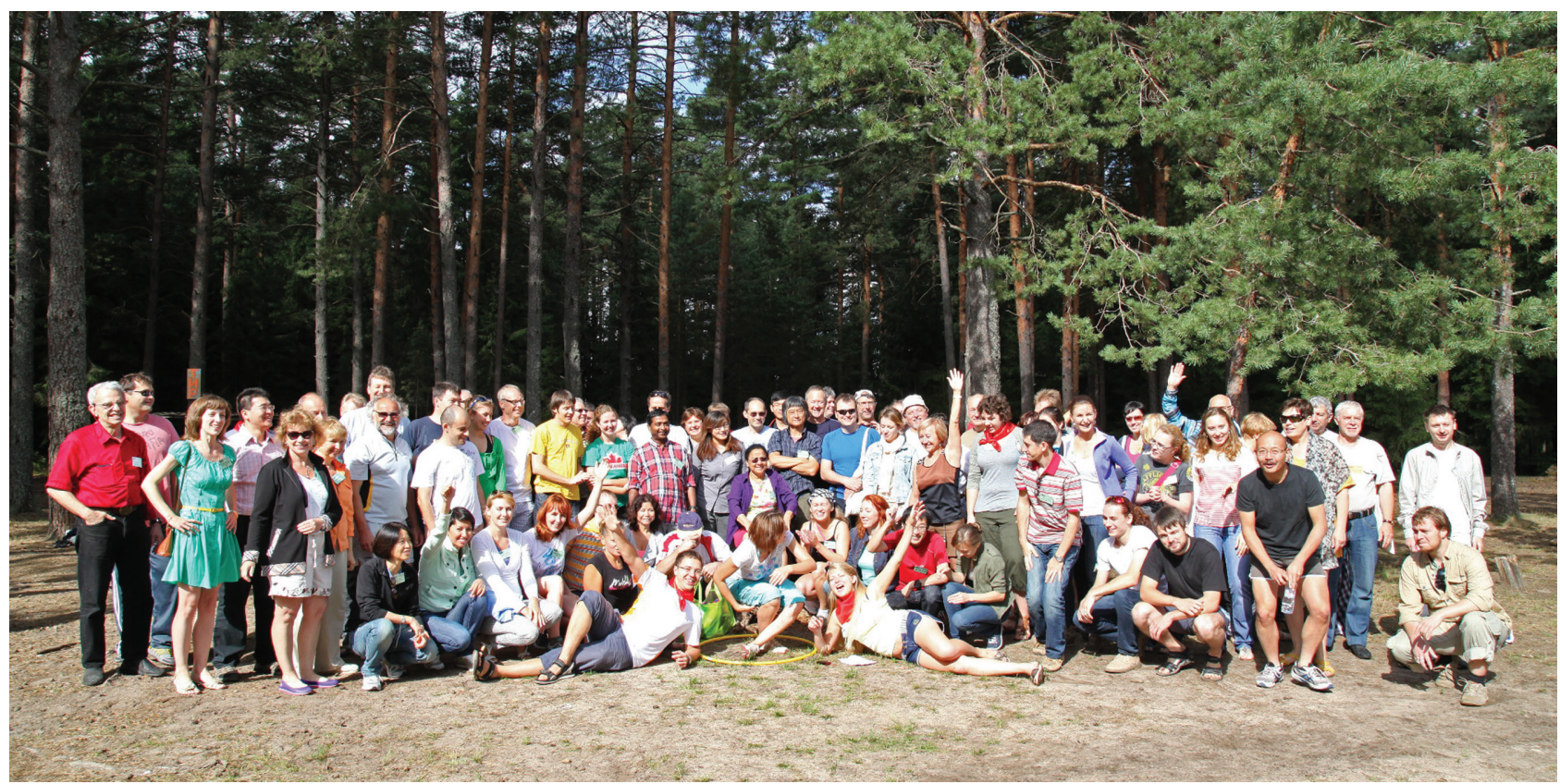

Conference group photo (photograph by S. Krotova).

Another translation of optical techniques into clinical practice is discussed in the study of ways for reduction of the effect of object displacement in the clinical application of opto-acoustic imaging combined with traditional ultrasound [15]. The final presentation in this issue is a technical note discussing the application of $\mathrm{THz}$ spectroscopy for analysis of exhaled breath [16]. Papers devoted to fluorescence imaging modalities (FLIM and whole-body imaging) will be published in the next issue of Photonics \& Lasers in Medicine [17, 18].

Finally, it is our pleasure to announce the forthcoming V International Symposium "Topical Problems of Biophotonics - 2015" that will be held on July 20-24, 2015 on board a ship travelling from Nizhny Novgorod to Yelabuga and back.

The symposium will include three parallel topical conferences: "Optical Bioimaging", "Nanobiophotonics", and "High-power Lasers in Biomedicine", as well as several workshops.

\section{References}

[1] Palshikar P, Sharma A, Chauhan CS, Kamble R. Biophotonics: a novel approach biomedical diagnosis. Int J Pharm Sci Rev Res 2013;21(1):350-4.

[2] Elson D, Anvari B. Biophotonics in bioengineering. Ann Biomed Eng 2012;40(2):250.
[3] Svanberg S. Biophotonics - techniques and applications. Laser Photonics Rev 2013;7(5):A43-4.

[4] Popp J, Tuchin VV, Chiou A, Heinemann SH, editors. Handbook of Biophotonics: Volume 1: Basics and techniques. Weinheim: Wiley-VCH Verlag GmbH \& Co. KGaA; 2011.

[5] Popp J, Tuchin VV, Chiou A, Heinemann SH, editors. Handbook of Biophotonics: Volume 2: Photonics for Health Care. Weinheim: Wiley-VCH Verlag GmbH \& Co. KGaA; 2011.

[6] Popp J, Tuchin VV, Chiou A, Heinemann SH, editors. Handbook of Biophotonics: Volume 3: Photonics in Pharmaceutics, Bioanalysis and Environmental Research. Weinheim: Wiley-VCH Verlag GmbH \& Co. KGaA; 2012.

[7] Bouma BE, Tearney G], editors. Handbook of optical coherence tomography. New York: Marcel Dekker; 2002.

[8] Drexler W, Fujimoto JG, editors. Optical coherence tomography: technology and applications. Heidelberg, New York, Dordrecht, London: Springer-Verlag; 2015.

[9] Elagin VV, Sergeeva EA, Bugrova ML, Ignatova NI, Yuzhakova DV, Denisov NN, Nadtochenko VA, Zagaynova EV. Selection of stabilizing agents to provide effective penetration of gold nanoparticles into cells. Photon Lasers Med 2014;3(4):351-62.

[10] Demidov V, Toronov V, Xu Y, Vuong B, Sun C, Yang V, Vitkin A. Imaging the electro-kinetic response of biological tissues with phase-resolved optical coherence tomography. Photon Lasers Med 2014;3(4):331-41.

[11] Kirillin M, Agrba P, Kamensky V. Mechanical compression in cross-polarization OCT imaging of skin: In vivo study and Monte Carlo simulation. Photon Lasers Med 2014;3(4):363-72.

[12] Davoudi B, Bizheva K, Wong A, Dinniwell R, Levin W, Vitkin A. Correlating optical coherence tomography images with dose distribution in late oral radiation toxicity patients. Photon Lasers Med 2014;3(4):311-21.

[13] Meller A, Shakhova M, Rilkin Y, Novozhilov A, Kirillin M, Shakhov A. Optical coherence tomography in diagnos- 
ing inflammatory diseases of ENT. Photon Lasers Med 2014;3(4):323-30.

[14] Matveev LA, Zaitsev VY, Matveev AL, Gelikonov GV, Gelikonov VM, Vitkin A. Novel methods for elasticity characterization using optical coherence tomography: Brief review and future prospects. Photon Lasers Med 2014;3(4):295-309.

[15] Jaeger M, Gashi K, Akarçay HG, Held G, Peeters S, Petrosyan T, Preisser S, Gruenig M, Frenz M. Real-time clinical clutter reduction in combined epi-optoacoustic and ultrasound imaging. Photon Lasers Med 2014;3(4):343-9.

[16] Vaks V, Domracheva E, Sobakinskaya E, Chernyaeva M. High-precision terahertz spectroscopy for noninvasive medicine diagnostics. Photon Lasers Med 2014;3(4):373-80.

[17] Kleshnin M, Shirmanova M, Fiks I, Orlova A, Plekhanov V, Zagainova E, Lukyanov S, Turchin I. Trans-illumination fluores- cence imaging of deep-seated tumors in small animals. Photon Lasers Med 2015. doi: 10.1515/plm-2014-0024.

[18] Becker W, Shcheslavskiy V. Fluorescence lifetime imaging with near-infrared dyes. Photon Lasers Med 2015. doi: 10.1515/plm2014-0017.

\section{Mikhail Kirillin*}

\section{Natalia Shakhova}

Ilya Turchin

*Corresponding author: Mikhail Kirillin, Institute of Applied Physics RAS, 603950 Ulyanov St. 46, Nizhny Novgorod, Russia, e-mail: mkirillin@yandex.ru

Natalia Shakhova and llya Turchin: Institute of Applied Physics RAS, 603950 Ulyanov St. 46, Nizhny Novgorod, Russia

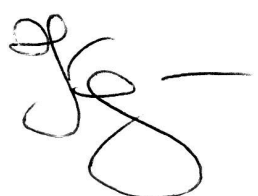

Mikhail Kirillin

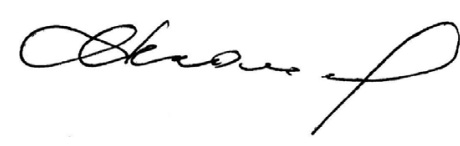

Natalia Shakhova

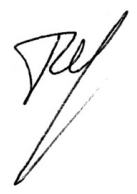

Ilya Turchin 